\title{
Canaloplasty versus Viscocanalostomy in Primary Open Angle Glaucoma
}

\author{
Faried Mohammed Wagdy
}

MD, Department of Ophthalmology, Faculty of Medicine, Menoufeya University, Egypt

\section{Type of article: Original}

\begin{abstract}
Introduction: The purpose of this study was to compare the efficacy and safety of canaloplasty versus viscocanalostomy in management of uncontrolled primary open angle glaucoma (POAG) with medication.

Methods: Canaloplasty surgery was applied for thirty eyes of thirty patients (45- 55 years) with a mean age of 48 years (Group A) and viscocanalostomy surgery was applied also for thirty eyes of thirty patients (43-54 years) with a mean age of 46 years (group B). All patients were with uncontrolled primary open angle glaucoma by maximally tolerated medical therapy.

Results: Intraocular pressure (IOP) in both surgeries was significantly reduced through follow up period ( $\mathrm{p}<$ 0.0 .001 ). Complete success was $86.6 \%$ in group A and $80 \%$ in group B. Visual field deterioration was in 2 cases $(6 \%)$ in group A and in 4 cases $(13 \%)$ in group B. Low incidence of postoperative complications was reported as Descemet's membrane detachment (3\% in group A and $8 \%$ in group B), ocular hypotony ( $2 \%$ in group A and $4 \%$ in group B) and hyphema (3\% in group A and $5 \%$ in group B).

Conclusion: Canaloplasty was more effective and safer than viscocanalostomy in management of uncontrolled primary open angle glaucoma (POAG) with medication.

Keywords: Canaloplasty, Viscocanalostomy, Glaucoma
\end{abstract}

\section{Introduction}

Filtering procedures in uncontrolled primary open angle glaucoma (POAG) with medication are associated with risk of postsurgical complications. Increasing interest in blebless surgery has led to innovative surgical procedures aimed at rejuvenating the natural trabeculo-canalicular outflow pathway (1). One of which is the viscocanalostomy in which there is a lower incidence of postoperative complications, thus offering both surgeon and patient a safer, more convenient option (2). Another recent technique named canaloplasty, aimed at a circumferential catheterization with suture tensioning of Schlemm's canal, has also emerged as a safe and effective way to surgically treat POAG (3). The objective of this research was to compare the efficacy and safety of canaloplasty versus viscocanalostomy in management of uncontrolled primary open angle glaucoma (POAG) with medication.

\section{Material and Methods}

Canaloplasty surgery was applied for thirty eyes of thirty patients (45-55 years) with a mean age of 48 years (Group A) and viscocanalostomy surgery was applied also for thirty eyes of thirty patients (43- 54 years) with a mean age of 46 years (group B). All patients were with uncontrolled primary open angle glaucoma by maximally tolerated medical therapy. Preoperative IOP ranged between $20-30 \mathrm{mmHg}$ in both groups with a mean of $27.2 \mathrm{mmHg}$ in group A and $26.4 \mathrm{mmHg}$ in group B. Exclusion criteria was included POAG with uncontrolled IOP above 30 $\mathrm{mmHg}$, other types of glaucoma, previous glaucoma surgery, any other ocular or systemic disease affecting vision or IOP. A complete ophthalmic examination was done preoperatively for all patients including best corrected visual acuity (BCVA), IOP with Goldmann applanation tonometer, gonioscopy using goniolens, slit lamp examination to assess the anterior segment of eye and biomicroscopy with volk lens +90 dioptre to assess posterior segment of the eye including optic disc examination. Octopus perimetry was carried out preoperatively in all patients.

\section{Corresponding author:}

Dr. Faried Mohammed Wagdy, Department of Ophthalmology, Faculty of Medicine, Menoufeya University, Egypt. Tel: +20.1001227987, E-mail: faried.wagdy@hotmail

Received: November 28, 2015, Accepted: August 17, 2016, Published: January 2017

iThenticate screening: February 08, 2016, English editing: November 10, 2016, Quality control: December 05, 2016 (C) 2017 The Authors. This is an open access article under the terms of the Creative Commons Attribution-NonCommercialNoDerivs License, which permits use and distribution in any medium, provided the original work is properly cited, the use is non-commercial and no modifications or adaptations are made. 


\subsection{Viscocanalostomy}

The surgical procedures are illustrated in Figures 1-5. Both surgeries were carried out either under general or local peribulbar anesthesia. Superior rectus bridle suture was taken, then a fornix based conjunctival flap was created extending from 2 to 10 o'clock. Bipolar cautery was not used as postoperative filtration will depend on the intrascleral and episcleral plexus of veins. Bleeding points were directly pressed on with a microsponge until hemostasis was achieved. A superficial square-shaped scleral flap $5.0 \times 5.0 \mathrm{~mm}(1 / 3$ of the scleral thickness $)$ was dissected to create a lamellar flap and extended about $0.5 \mathrm{~mm}$ into clear cornea. A second smaller square or triangular flap was dissected $0.5 \mathrm{~mm}$ inside the border of the initial flap and extended into clear cornea for about 0.5 $\mathrm{mm}$. In some cases the second deep flap dissection was done by blade 15 and in other cases that was done by diamond knife. This second flap constituted approximately $2 / 3$ of the scleral thickness to leave a thin translucent layer of sclera overlying the uvea. Two important surgical land marks appeared if dissection was done in the correct surgical plane: the color change from the scleral white to the blue zone of the trabecular meshwork, and the change of direction of the deeper scleral collagen bundles. Then the Schlemm's canal (SC) was unroofed, and was readily visualized approximately $1.0 \mathrm{~mm}$ posterior to the limbus. Two surgical slits were then made on either side of the deeper flap to create the surgical ostia in the SC. Sometimes a gush of aqueous was noticed from the opened ends of the SC. A finely polished cannula (outer diameter $150 \mathrm{um}$ ) was then introduced into the ostia of SC. both right and left, to inject high viscosity sodium hyaluronate (4\%) for 4.0 to $6.0 \mathrm{~mm}$ on each side. Gentle pressure on Schwalbe's line using a cellulose sponge was then applied to separate the Descement's membrane from the corneoscleral junction and create an intact window in Descement's membrane through which aqueous started to percolate from the AC into the Subscleral Lake. The deeper scleral flap was then excised at its base using a Vannas scissors .Five 10/0 nylon sutures were used to suture the superficial flap in a watertight manner. High viscosity sodium hyaluronate was injected into the subscleral lake to help as a space maintainer and acts as a physical barrier to fibrinogen migration postoperatively. The conjunctival flap was sutured using 8-0 silk sutures. The first step was to take the superior rectus bridle suture, followed by the formation of a fornix based conjunctival flap extending from 2 to 10 o'clock. There was no bipolar cautery, as postoperative filtration is based upon the intrascleral and episcleral plexus of veins. To achieve hemostasis, bleeding points were directly pressed on with a microsponge. A superficial square-shaped scleral flap $1 / 3$ of the scleral thickness $(5.0 \times 5.0 \mathrm{~mm})$ was dissected to create a lamellar flap and extended about 0.5 $\mathrm{mm}$ into clear cornea. A secondary square or triangular flap, smaller than the initial flap, was dissected $0.5 \mathrm{~mm}$ inside the border of the initial flap and extended into clear cornea for approximately $0.5 \mathrm{~mm}$. For some cases, blade 15 was used to carry out the second deep flap dissection and at other times, diamond knife was used. The second flap was approximately $2 / 3$ of the scleral thickness leaving a thin translucent layer of sclera overlying the uvea. Dissection in the correct surgical plane would reveal two important surgical land marks: the scleral white would change to the blue zone of the trabecular meshwork, and there would be a change in direction of the deeper scleral collagen bundles. Next the Schlemm's canal (SC) was unroofed, and was readily visualized about $1.0 \mathrm{~mm}$ posterior to the limbus. Then, on either side of the deeper flap, two surgical slits were made, creating the surgical ostia in the SC. A flow of aqueous was sometimes noticed emitting from the opened ends of the SC. Next, a highly-polished cannula (outer diameter $150 \mathrm{um}$ ) was introduced into both right and left of the ostia of SC, to inject high viscosity sodium hyaluronate (4\%) for 4.0 to $6.0 \mathrm{~mm}$ on either side. Using a cellulose sponge, slight pressure was then applied to Schwalbe's line in order to separate the Descemet's membrane from the corneoscleral junction and form an intact window in Descemet's membrane through which aqueous began to percolate from the AC into the Subscleral Lake. Then, using a Vannas scissors, the deeper scleral flap was excised at its base. To suture the superficial flap in a watertight manner, five 10/0 nylon sutures were used. To help as a space maintainer and also act as a physical barrier to fibrinogen migration postoperatively high viscosity sodium hyaluronate was injected into the Subscleral Lake. The conjunctival flap was sutured using 8-0 silk sutures.

\subsection{Canaloplasty}

The same steps were carried out until reaching superficial scleral flap, half-thickness triangular scleral flap, followed by a deep scleral flap that exposes and unroofs Schlemm's canal and creates a Descemet's window. The deep flap is excised and removed. A $250-\mu \mathrm{m}$ catheter with a fiber optic light and lumen (for injection of viscoelastic) on its end is inserted into Schlemm's canal; the catheter is gently passed around the circle until the tip emerges on the other side (Figure 5). A suture is then tied to the catheter. As the catheter's direction is reversed and it is pulled out of the canal, the suture replaces it. The suture is then tied tightly enough to stent the canal open. Finally, the superficial scleral flap and conjunctiva are closed so as to be watertight. 


\subsection{Postoperative follow up}

Postoperative follow up visits were carried out at one day, one month and then monthly for six months after surgery. The patients in the study were subjected to a complete ophthalmologic examination for up to six months which included: 1) IOP monitoring, 2) Anterior segment examination, 3) Visual acuity examination, 4) Fundus and optic nerve head examination using fundus biomicroscopy, 5) Visual field examination after six months, and 6) recording of any intraoperative and postoperative complications.

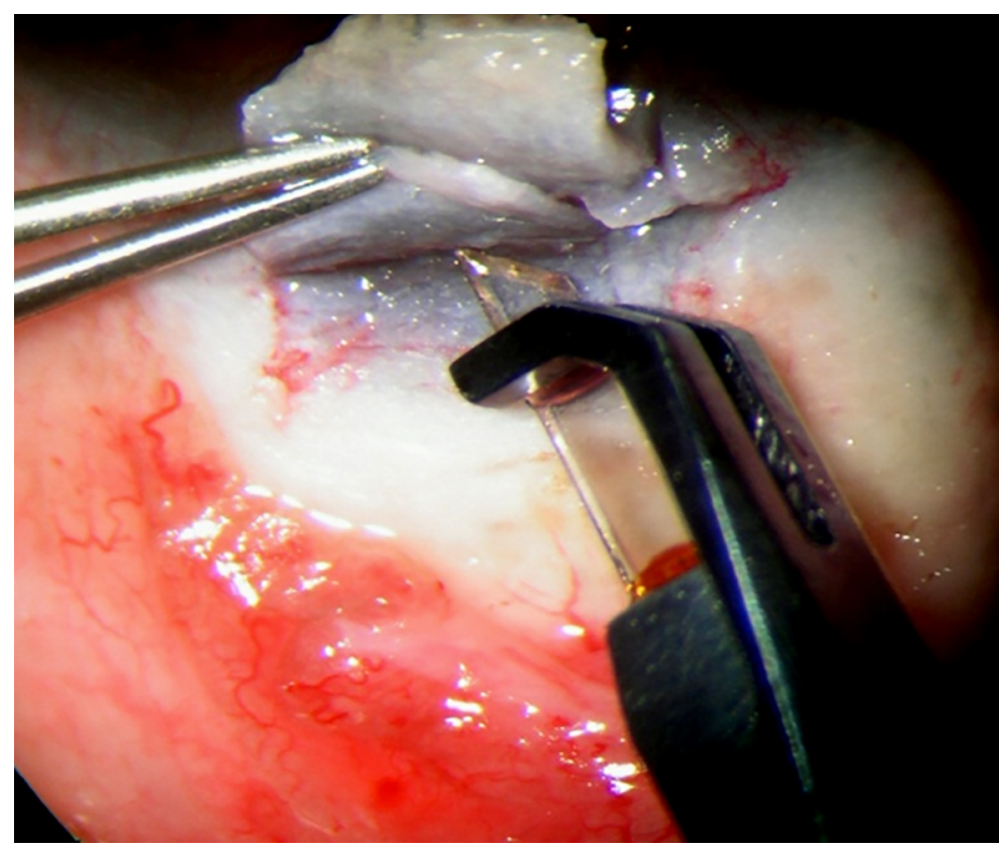

Figure 1. The dissection of deep scleral flap by diamond knife

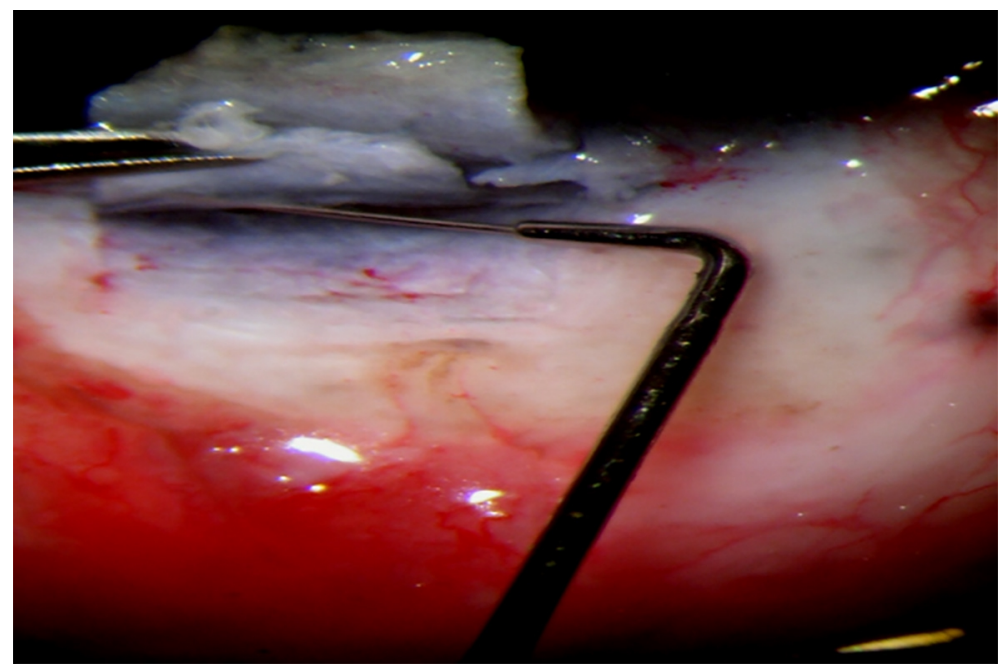

Figure 2. The injection of high viscosity Healon by the viscocanalostomy cannula into S.C in right and left directions 


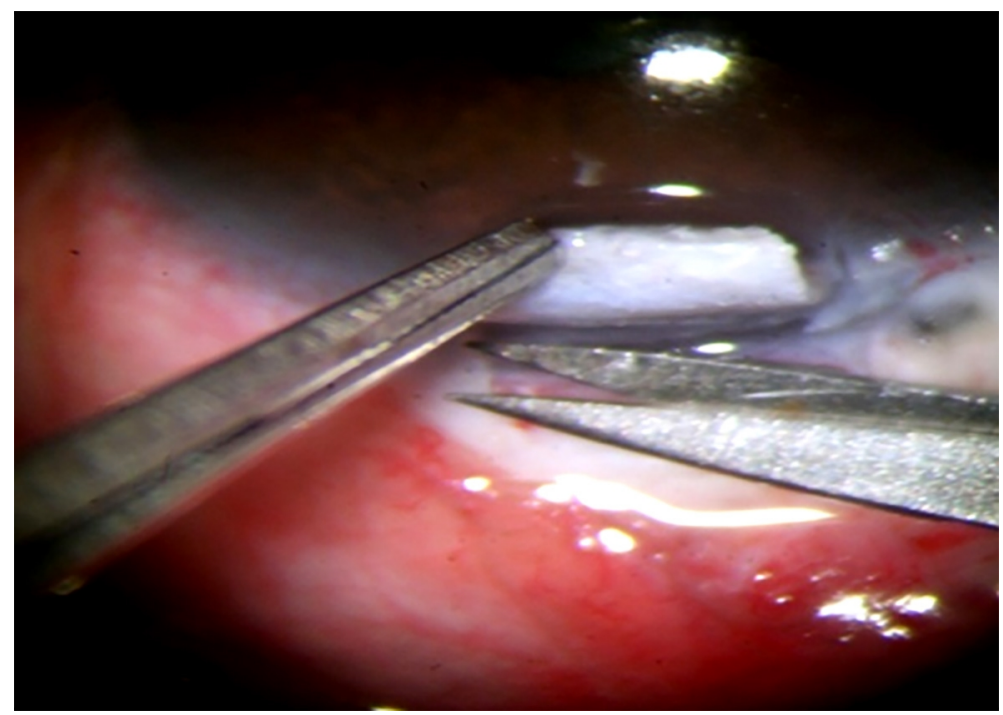

Figure 3. Excision of the deep scleral flap

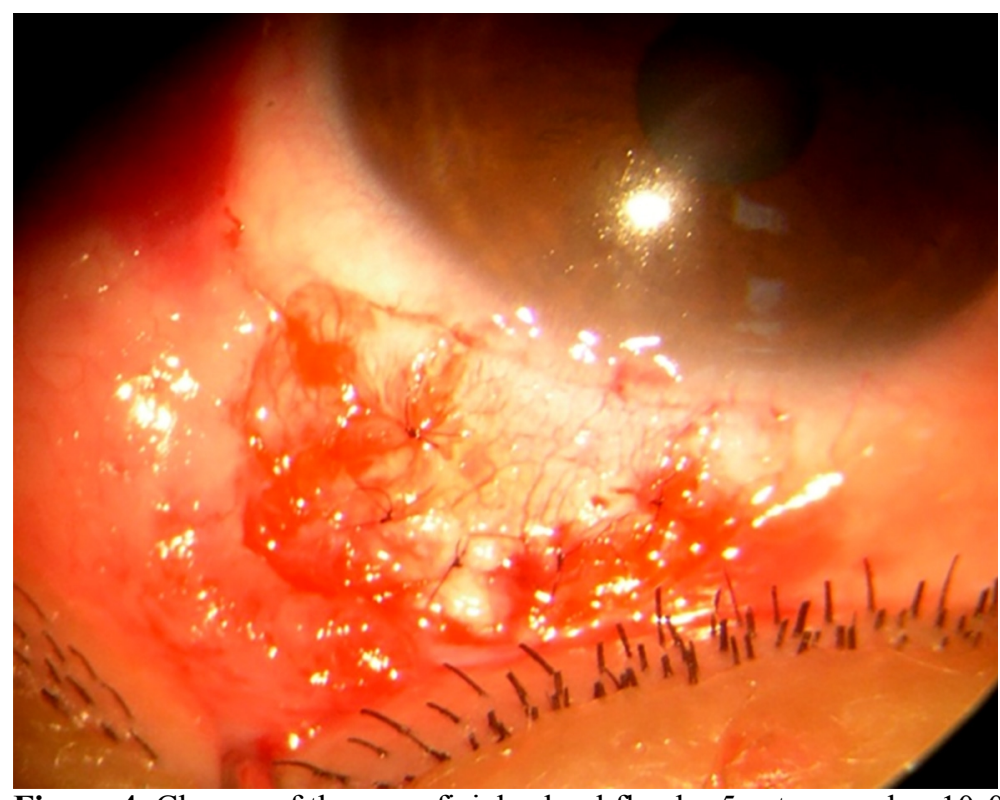

Figure 4. Closure of the superficial scleral flap by 5 sutures nylon 10-0

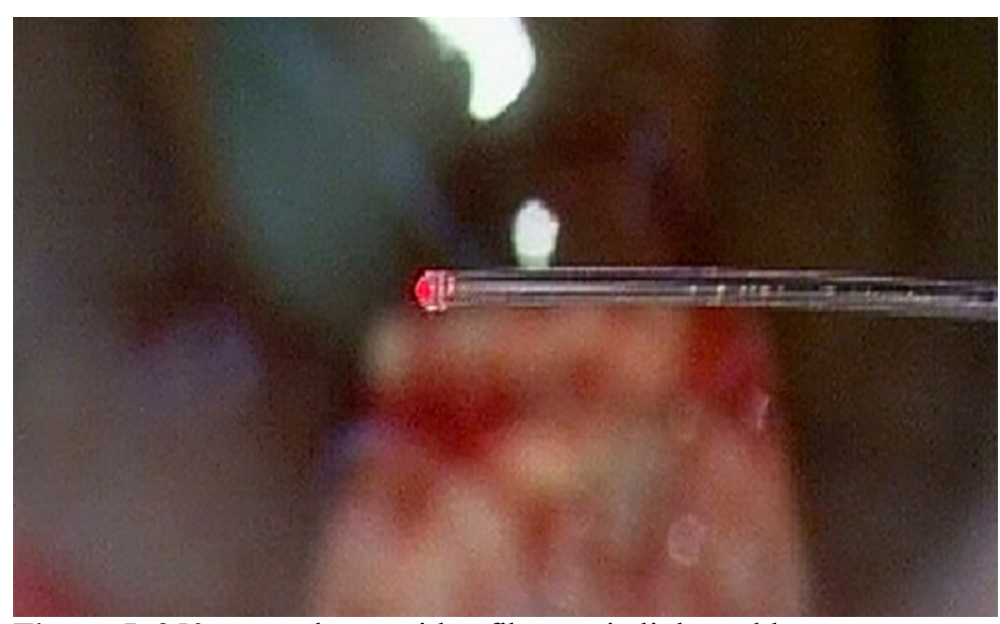

Figure 5. $250-\mu \mathrm{m}$ catheter with a fiber optic light and lumen 


\section{Results}

The study disclosed a considerably significant reduction in IOP postoperatively in canaloplasty and viscocanalostomy throughout a six-month period as $p<0.001$ with greater reduction in canaloplasty than viscocanalostomy. In group A (canaloplasty), the mean IOP of the studied eyes was $27.2 \pm 1.9$, which was reduced to $15.8 \pm 3.4$ in the first postoperative day with more reduction to $15.5 \pm 1.2$ within the first month, and after one year (mean IOP $=15.6 \pm 1.2)$ and with a high significant reduction in IOP $(\mathrm{p}<0.001)$, while in group B (viscocanalostomy), the mean IOP of the studied eyes was $26.4 \pm 2.95$, which was reduced to $17.4 \pm 1.38$ in the first postoperative day with more reduction within the first month to $16.9 \pm 1.32$ and after one year (mean IOP $=16.8 \pm$ $1.49)$ with a high significant reduction in IOP $(\mathrm{p}<0.001)$ (Tables 1 and 2$)$. IOP reduction in both groups was more significant at 1 and 6 months when compared to first postoperative day $(\mathrm{p}<0.001)$ as seen in Table 3 while difference in IOP reduction was less significant between 1 and 3 months $(p>0.05)$ as described in Table 4. Complete success was $86.6 \%$ in group A and $80 \%$ in group B. The study represented significant stability of the visual acuity $(\mathrm{p}<0.001)$ with only 1 case with one line drop of visual acuity in group A $(3 \%)$ and only 3 cases with one line drop of visual acuity in group B $(10 \%)$. Visual field deterioration was in 2 cases $(6 \%)$ in group A and in 4 cases (13\%) in group B. Incidence of postoperative complications was less in canaloplasty (group A) than in viscocanaloplasty in form of Descemet's membrane detachment (3\% in group A and $8 \%$ in group B), ocular hypotony (2\% in group A and $4 \%$ in group B) and hyphema (3\% in group A and $5 \%$ in group B).

Table 1. Mean (SD) of preoperative IOP versus postoperative IOP in both surgeries

\begin{tabular}{|c|c|c|c|c|c|c|c|}
\hline \multirow[t]{3}{*}{ Groups } & \multirow[t]{3}{*}{ Preoperative IOP } & \multicolumn{6}{|c|}{ Postoperative IOP } \\
\hline & & \multicolumn{2}{|l|}{$1^{\text {st }}$ day } & \multicolumn{2}{|l|}{$1^{\text {st }}$ month } & \multicolumn{2}{|l|}{$6^{\text {th }}$ month } \\
\hline & & Mean \pm SD & p-value & Mean \pm SD & $p$-value & Mean \pm SD & $p$-value \\
\hline Group A & $27.2 \pm 1.9$ & $15.8 \pm 3.4$ & $<0.001$ & $15.5 \pm 1.2$ & $<0.001$ & $15.6 \pm 1.2$ & $<0.001$ \\
\hline Group B & $26.4 \pm 2.95$ & $17.4 \pm 1.38$ & $<0.001$ & $16.9 \pm 1.32$ & $<0.001$ & $16.8 \pm 1.49$ & $<0.001$ \\
\hline
\end{tabular}

Table 2. Postoperative IOP reduction at 1 month and 6 months

\begin{tabular}{|l|l|l|}
\hline \multirow{2}{*}{ Follow up } & \multicolumn{2}{|l|}{ Mean difference in IOP reduction } \\
\cline { 2 - 3 } & Group A & Group B \\
\hline $1^{\text {st }}$ day & 11.4 & 9 \\
\hline $1^{\text {st }}$ month & 11.7 & 9.5 \\
\hline $6^{\text {th }}$ month & 11.6 & 9.6 \\
\hline
\end{tabular}

Table 3. Postoperative IOP reduction at 1 month and 6 months in comparison to first postoperative day IOP

\begin{tabular}{|l|l|l|l|l|l|}
\hline Groups & $1^{\text {st }}$ day & \multicolumn{2}{|l|}{$1^{\text {st }}$ month } & \multicolumn{2}{l|}{$6^{\text {th }}$ month } \\
\cline { 3 - 6 } & & Mean \pm SD & p-value & Mean \pm SD & p-value \\
\hline Group A & $15.8 \pm 3.4$ & $15.5 \pm 1.2$ & $<0.001$ & $15.6 \pm 1.2$ & $<0.001$ \\
\hline Group B & $17.4 \pm 1.38$ & $16.9 \pm 1.32$ & $<0.001$ & $16.8 \pm 1.49$ & $<0.001$ \\
\hline
\end{tabular}

Table 4. Postoperative IOP reduction at 1 month and 6 months

\begin{tabular}{|l|l|l|l|}
\hline Groups & $1^{\text {st }}$ month & $6^{\text {th }}$ month & p-value \\
\hline Group A (Mean \pm SD) & $15.5 \pm 1.2$ & $15.6 \pm 1.2$ & $>0.05$ \\
\hline Group B (Mean \pm SD) & $16.9 \pm 1.32$ & $16.8 \pm 1.49$ & $>0.05$ \\
\hline
\end{tabular}

\section{Discussion and conclusions}

When using the microcatheter with suture tensioning of Schlemm's canal, canaloplasty is a minimally invasive method in which to treat OAG surgically. Moreover, this procedure results in a reduction of intraocular pressure (IOP) without formation of a conjunctival bleb. However, canaloplasty has its constraints as technically, the surgery can be challenging and there is a definite learning curve (4). Furthermore, not every patient with glaucoma is a suitable candidate for canaloplasty. The procedure is contraindicated to patients with angle recession, chronic angle closure, neovascular glaucoma, a narrow angle glaucoma, and those with previous ocular surgery which would prevent circumferential catheterization of Schlemm's canal (5). Also Viscocanalostomy is one of the non-penetrating glaucoma surgeries firstly described by Stegmann in South Africa in 1999. The concept depended on the injection of a high viscosity sodium hyaluronate in order to dilate the Schlemm's canal, thus creating micro perforations in its wall, to facilitate aqueous passage from anterior chamber to the canal lumen. That was associated with formation of a subscleral lake which allowed the aqueous passage from the anterior chamber through an intact Descemet's 
window which then passed into the dilated ostia of the Schlemm's canal. Finally, aqueous flows to the deep and intrascleral venous plexus and then into the ciliary veins (6). In this study, there was a considerably significant reduction in IOP postoperatively in canaloplasty and viscocanalostomy over 6 months as $p<0.001$ with more reduction in canaloplasty than viscocanalostomy. In canaloplasty (group A), the mean IOP of the studied eyes was $27.2+1.9$, which was reduced to $15.8+3.4$ in the first postoperative day with more reduction at first month to $15.5+$ 1.2 and until after one year (mean $\mathrm{IOP}=15.6+1.2)$ with a high significant reduction in IOP $(\mathrm{p}<0.001)$, while in viscocanalostomy (group B), the mean IOP of the studied eyes was $26.4 \pm 2.95$, which was reduced to $17.4 \pm 1.38$ in the first postoperative day with more reduction at first month to $16.9 \pm 1.32$ and until after one year (mean IOP= $16.8 \pm 1.49)$ with a high significant reduction in IOP $(\mathrm{p}<0.001)$. The study also represented significant stability of the visual acuity and visual field with low incidence postoperative complications, which was less in canaloplasty (group A) than in viscocanaloplasty in form of Descemet's membrane detachment (3\% in group A and $8 \%$ in group B), ocular hypotony ( $2 \%$ in group A and 4\% in group B) and hyphema (3\% in group A and 5\% in group B). These results were similar to results obtained by Peckar and Koerber in 2008, in which both Canaloplasty and Viscocanalostomy groups showed a statistically significant reduction in IOP and number of medication from preoperative levels. Statistically, there was a considerable difference in favor of the canaloplasty group in postoperative reduction of both IOP amount of medication in comparison to the viscocanalostomy group (7). These results were also in agreement with a study done by Koerber in 2012. In the viscocanalostomy cohort, eyes had a mean IOP of $16.1 \pm 3.9 \mathrm{~mm} \mathrm{Hg}$ on $0.4 \pm 0.5$ medication at 18 months as compared with preoperative levels of 24.3 $\pm 2.8 \mathrm{~mm} \mathrm{Hg}$ on $1.9 \pm 0.8$ medication $(\mathrm{p}=0.02)(8)$.Various studies throughout the world presented the role of canaloplasty and viscocanalostomy in POAG, one of which was done by Shaarawy et al. in 2003 which described the significant reduction of preoperative IOP by viscocanalostomy. In a study by Lewis et al., eyes with canaloplasty alone had a mean IOP of $16.3 \pm 3.7 \mathrm{mmHg}$ and $0.6 \pm 0.8$ medication (4). Surgical complications were reported in five eyes of which three had hyphema and one each had a Descemet tear and iris prolapse (9). Although canaloplasty results in IOPs in the mid-teens, trabeculectomy has been shown to decrease IOP more significantly. Further, clinical data shows that very low IOP is necessary to treat OAG (10-12). Therefore, canaloplasty seems to be more effective and safer than viscocanalostomy in management of uncontrolled POAG with medication.

\section{Acknowledgments:}

Nothing to acknowledge.

\section{Conflict of Interest:}

There is no conflict of interest to be declared.

\section{References:}

1) Harvey BJ, Khaimi MA. A review of canaloplasty. Saudi J Ophthalmol. 2011; 25(4): 329-36. doi: 10.1016/j.sjopt.2011.08.003. PMID: 23960946, PMCID: PMC3729506.

2) Shaarawy T, Nguyen C, Schnyder C, Mermoud A. Five year results of viscocanalostomy. Br J Ophthalmol. 2003; 87(4): 441-5. doi: 10.1136/bjo.87.4.441. PMID: 12642307, PMCID: PMC1771626.

3) Khaimi MA. Canaloplasty using iTrack 250 Microcatheter with Suture Tensioning on Schlemm's Canal. Middle East Afr J Ophthalmol. 2009; 16(3): 127-9. doi: 10.4103/0974-9233.56224. PMID: 20142977, PMCID: PMC2813597.

4) Lewis RA, von Wolff K, Tetz M, Koerber N, Kearney JR, Shingleton BJ, et al. Canaloplasty: circumferential viscodilation and tensioning of Schlemm's canal using a flexible microcatheter for the treatment of open-angle glaucoma in adults: Two-year interim clinical study results. J Cataract Refract Surg. 2009; 35(5): 814-24. doi: 10.1016/j.jcrs.2009.01.010. PMID: 19393879.

5) Godfrey DG, Fellman RL, Neelakantan A. Canal surgery in adult glaucomas. Curr Opin Ophthalmol. 2009; 20(2): 116-21. doi: 10.1097/icu.0b013e32831eef65. PMID: 19240543.

6) Shaarawy T, Mermoud A. Atlas of glaucoma surgery. Jaypee Brothers medical publishers, New Delhi chapter. 2006; 8: 102-9: 112.

7) Peckar C, Korber N. Canaloplasty for open angle glaucoma: a three years critical evaluation and comparison with viscocanalostomy. Spektrum der Augenheilkunde September. 2008; 22(4): 240-6. doi: 10.1007/s00717-008-0272-y.

8) Korber NJ. Canaloplasty in one eye compared with viscocanalostomy in the contralateral eye in patients with bilateral open-angle glaucoma. J Glaucoma. 2012; 21(2): 129-34. doi: 10.1097/IJG.0b013e31820277c0. PMID: 21278587. 
9) Shingleton B, Tetz M, Korber N. Circumferential viscodilation and tensioning of Schlemm canal (canaloplasty) with temporal clear corneal phacoemulsification cataract surgery for open-angle glaucoma and visually significant cataract; one-year results. J Cataract Refract Surg. 2008; 34(3): 433-40. doi: 10.1016/j.jcrs.2007.11.029. PMID: 18299068.

10) Feiner L, Piltz JR. Collaborative Initial Glaucoma Treatment Study: a summary of results to date. Curr Opin Ophthalmol. 2003; 14(2): 106-11. doi: 10.1097/00055735-200304000-00010. PMID: 12698052.

11) Musch DC, Gillespie BW, Lichter PR, Niziol LM, Janz NK. Visual field progression in the Collaborative Initial Glaucoma Treatment Study the impact of treatment and other baseline factors. Ophthalmology. 2009; 116(2): 200-7. doi: 10.1016/j.ophtha.2008.08.051. PMID: 19019444, PMCID: PMC3316491.

12) Ayyala RS, Chaudhry AL, Okogbaa CB, Zurakowski D. Comparison of surgical outcomes between canaloplasty and trabeculectomy at 12 months' follow-up. Ophthalmology. 2011; 118(12): 2427-33. doi: 10.1016/j.ophtha.2011.05.021. PMID: 21856008. 